\title{
Bilateral variations in the roots of origin of the phrenic nerve and absence of fibrous pericardium in an old male cadaver
}

\author{
AHMADPOUR, S. ${ }^{*}$ and FOGHI, $\mathrm{K}$. \\ Anatomical Sciences Department, Medicine School, North Khorasan University of Medical Sciences, Bojnurd, Iran \\ *E-mail: Shahahmadpour@gmail.com
}

\begin{abstract}
Phrenic nerve provides the major motor supply to diaphragm. Various anatomical variations in the course and distribution of the phrenic nerve have reported before. Here we report a rare bilateral asymmetric variation in the roots of origin of the phrenic nerve and absence of fibrous pericardium in an old male cadaver. Specifically, the right phrenic nerve was arising from the upper trunk of the brachial plexus (C5) and the left side nerve originated from the supraclavicular nerve and a tiny branch from C5. In the same cadaver both sides phrenic nerve were buried in the mediastinal pleura. Another interesting finding was absence of the fibrous pericardium. To the best of our knowledge the presented case showed a very rare variation in the roots of origin of the phrenic nerve accompanied with pericardial anomaly which has been less reported. We think such case is of practical importance during supraclavicular block during anesthesia
\end{abstract}

Keywords: phrenic nerve, brachial plexus, supraclavicular, fibrous pericardium.

\section{Introduction}

Phrenic nerve provides motor supply to the diaphragm. It is formed predominantly by the ventral rami of $\mathrm{C} 4$ with contributions from C3 and C5 behind the prevertebral fascia at the lateral border of scalenus anterior and descends in front of it (CLEMENTE, 1985). At the root of the neck it runs vertically downwards, sandwiched between subclavian vein and artery. It descends between fibrous pericardium and mediastinal parietal pleura, supplying pericardium, pleura and diaphragm (BERGMAN, THOMPSON, AFIFI et al., 1988). The anatomical variations of the phrenic nerve is of great importance due to possible complete paralysis of diaphragm particularly in patients undergoing supraclavicular block (MENDELSOHN, DECONDE, LAMBERT et al., 2011). Furthermore a thorough knowledge of the cervical variations of the phrenic nerve could be worthwhile in restorative surgeries in neck region (BIGELEISEN, 2003). Here we are reporting a bilateral asymmetry of the phrenic nerve in neck region accompanied with absence of fibrous pericardium in an old male cadaver.

\section{Case Report}

During a routine educational dissection in a 76-year-old male, the phrenic nerve was traced by dissection in both sides. We observed a rare bilateral variation of the phrenic nerve. The right phrenic nerve was arising from C5 of the upper trunk of the brachial plexus at the lateral border of scalenus anterior muscle under the prevertebral fascia and sternocleidomastoid muscle. The right phrenic nerve runs downwards from lateral border of scalenus anterior muscle to its anterior surface (Figure 1). Then the authors traced the phrenic nerve of the left side of the neck. The left nerve originated from supraclavicular nerve at the level of the upper border of thyroid cartilage, descending deep to prevertebral fascia. The nerve just above the upper trunk of the brachial plexus received a small communicating branch from C5 (Figure 2). The course of the nerve was examined in the thorax. The right and left phrenic nerves were buried partly inside the mediastinal parietal pleura. In the same cadaver, in situ inspection of the heart revealed that fibrous pericardium is absent and only a transparent thin layer adhered intimately to the heart (Figure 3). The transparent pericardium closely attached to the cardiac surfaces. Inferiorly it is attached to the central tendon of diaphragm and near the inferior border some muscular fibers blend with pericardium. After pericardial sac incision, cardiac pouches were examined. The transverse sinus formed a $4 \mathrm{~cm}$ in length cul- de -sac posterior to the ascending aorta opening it to the right side. The diameter of siotubular junction and proximal part of ascending aorta were measured $1.7 \mathrm{~cm}$ and 3.5 respectively. Close inspection revealed an abnormal constriction in sinotubular junction of ascending aorta.

\section{Discussion}

To date numerous anatomical variations of the phrenic nerve has been described. The phrenic nerve may receive additional spinal roots from one or more of the following nerves; nerve to subclavius, nerve to sternohyoid, C2 or rarely C6, descendens cervicalis; ansa cervicalis and brachial plexus or receive a branch from hypoglossal nerve and may communicate with CN XI (spinal accessory) (BANNEHEKA, 2008). The case presented here showed a bilateral asymmetry in the root of the phrenic nerve. The right nerve originated from C5 alone, while in the left, the nerve originated from supraclavicular nerve and C5. Mendelsohn, Deconde, Lambert et al. (2011) studied the variations of the phrenic nerve (sample size 110 cadaver). Their study showed the most common pattern of the phrenic nerve consists of phrenic nerve with single $\mathrm{C} 3$ and $\mathrm{C} 4$ rootles with an immeasurable C5 which was present in $26 \%$ of the necks. 


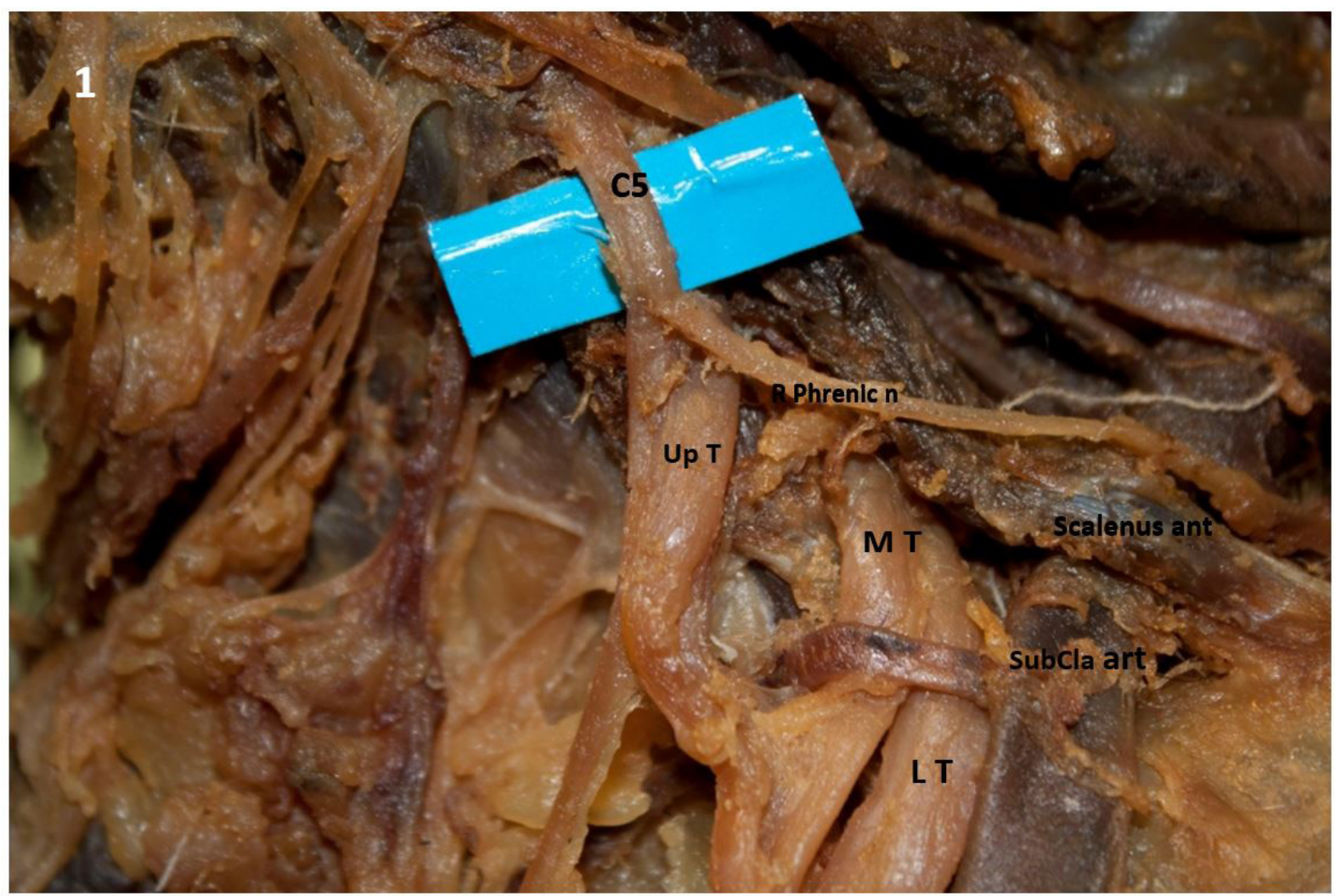

Figure 1. The right phrenic nerve ( $\mathbf{R}$ phrenic nerve) originates from C5 root of the upper trunk (UP) of the brachial plexus. The phrenic nerve descends in front of scalenus anterior (scalenus ant). Middle, lower trunk of the brachial plexus (MT, LT), subclavian artery (Sub cla art).

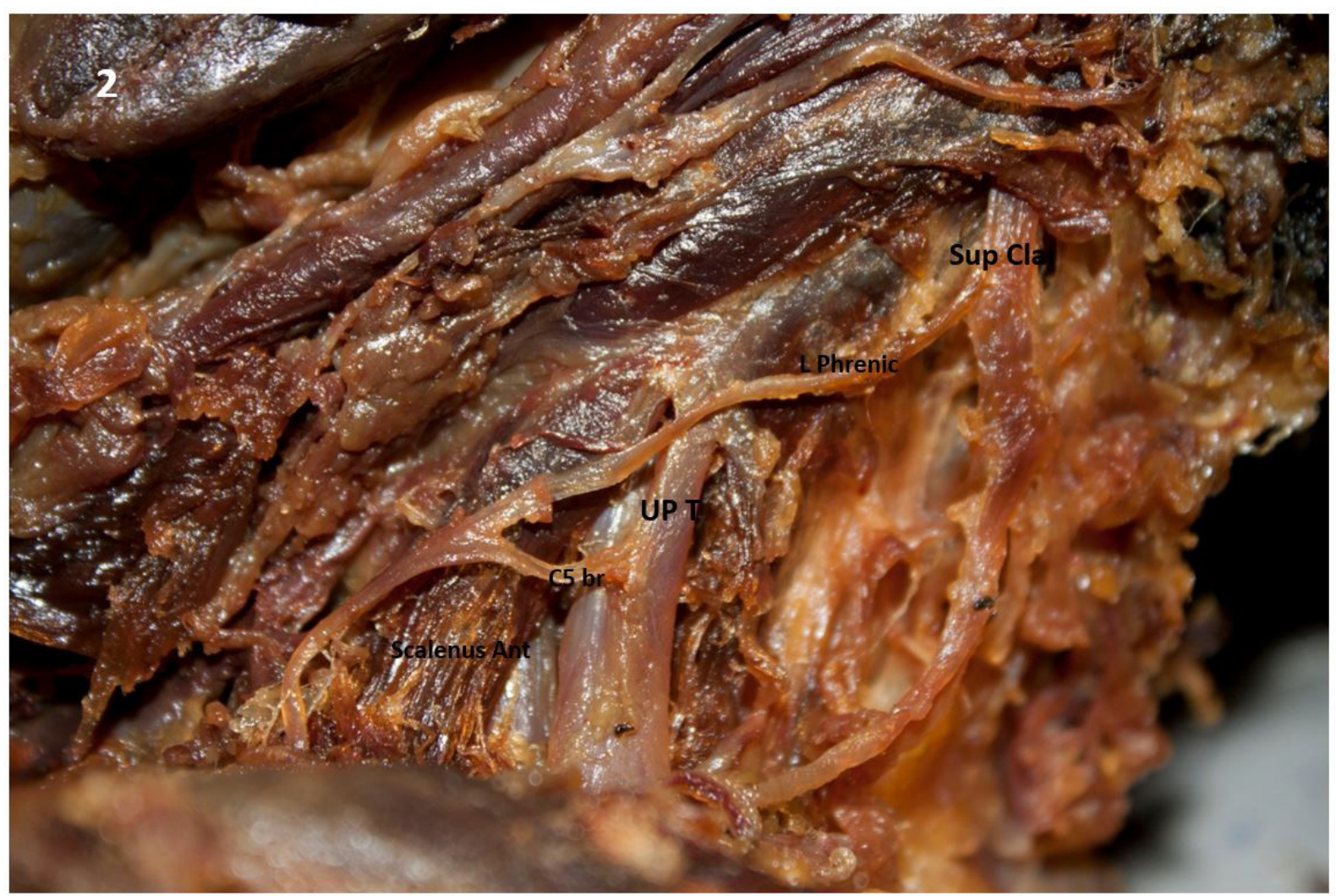

Figure 2. The left phrenic nerve ( $R$ phrenic nerve) originates from the supraclavicular nerve (Sup cla) and a branch from C5 (C5 br) root of the upper trunk (UP) of the brachial plexus. The left phrenic nerve descends in front of scalenus anterior (scalenus ant). 


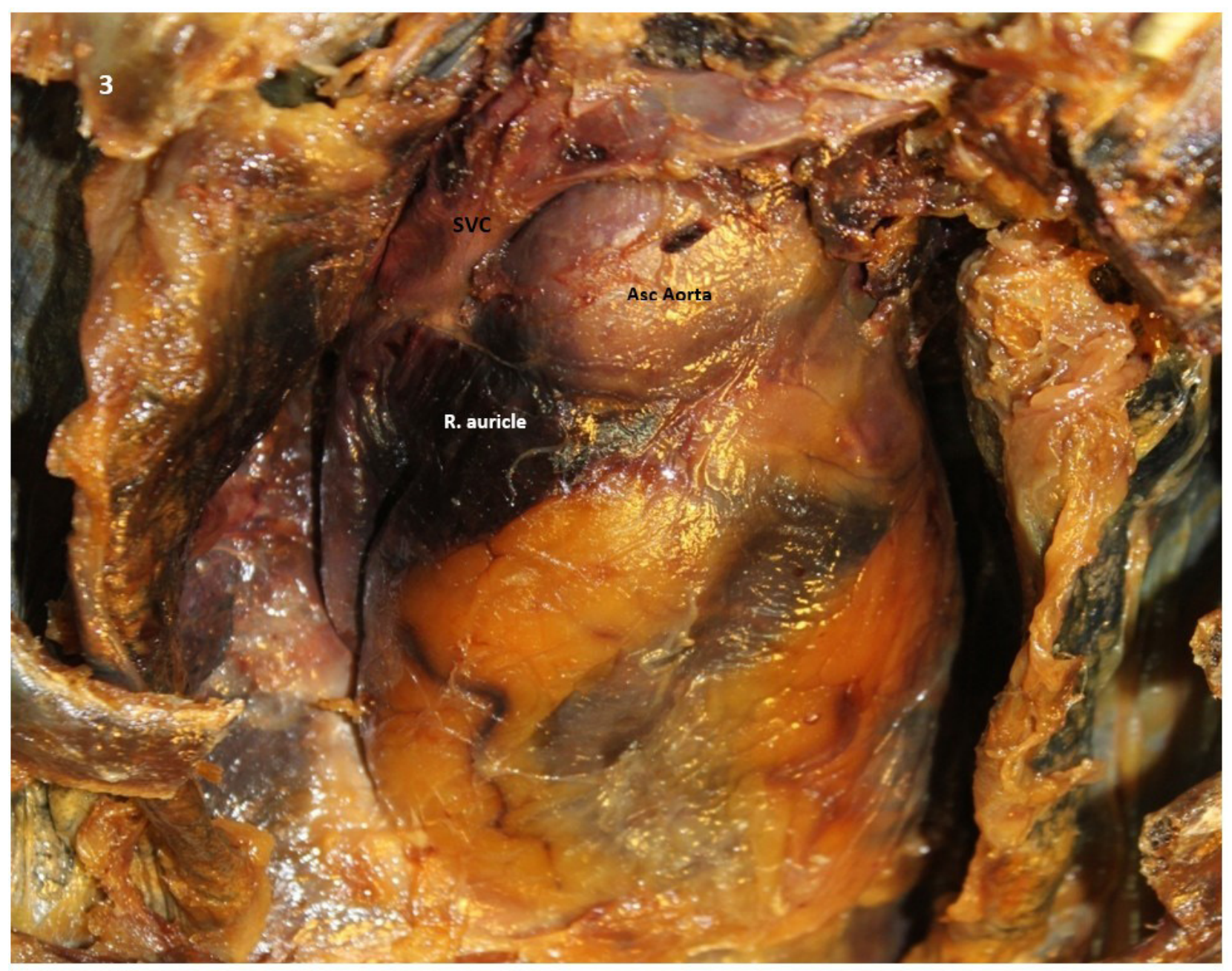

Figure 3. Heart without fibrous pericardium in a vertical position. Superior vena cava (SVC), Right auricle (R auricle), Ascending aorta (Asc Aorta).

Banneheka (2008) in a cadaveric study( 106 cadavers $)$ reported in $52 \%$ of the cases the phrenic originated from $\mathrm{C} 4$ and $\mathrm{C} 5$ and only in one case $\mathrm{C} 4$ segment was absent.

Aktan, Ozturk, Bilge et al. (2006) in their cadaveric study of the brachial plexus, reported a case that left phrenic nerve was connected with superior trunk. Madhystha and Bhat (2006) reported a bilateral variation in the origin of the phrenic nerve arising from supraclavicular nerve on both side with a communicating branch from the superior trunk of the brachial plexus. Dayal and Ky (2009) studied the variations in the roots of origin of the phrenic nerve. In their study only on two sides the phrenic nerve was observed to originate from C3, 4 and 5(classical described). In majority of the dissected cases the phrenic nerve originated from C3 alone (36.84\%), C3, C4 (28.95\%) and C4 alone (18.42\%). The presented case here is an instance of asymmetry in the roots of the phrenic nerve. To the best of our knowledge such variations in the roots origin of the phrenic from C5 alone in one side and supraclvicular communicating with the upper trunk of the brachial plexus in other side have not been reported before. Given that the variations of the root origin of the phrenic nerve are asymptomatic and not life threatening, but their clinical importance become more evident during supraclavicular block procedure (BIGELEISEN, 2003). Anesthetic block can lead to complete paralysis of the ipsilateral hemidiaphragm and post operative complications (MAK, 2001). Another set of our findings revealed some variations of the pericardium. Although such subsidiary findings seem to be unimportant and irrelevant, they are of academic interest. Congenital absence of the pericardium is rare and frequently is identified at postmortem time or during medical interventions (TARIG, MAHMOOD, MADEIRA et al., 2013) E.Pericardium development begins in the third week of embryonic life, when embryonic celoum is divided into pericardial, peritoneal and pleural cavities. By the fourth week, septum transversum grows and separates the primitive pericardial from the peritoneal cavity .The division, however, is not complete: pericardio-peritoneal canals remain on both sides, medial to the common cardinal veins (ducts of Cuvier). Finally the pericardio- peritoneal canals are obliterated by two membranous folds dorsally (pleura-peritoneal) and ventrally (pleura-pericardial) (ELLIS, 2005). Main theories on congenital pericardium defects assume the causative factors interfere with closure of these folds (KOO and NEWBURG, 2015). To date six types of congenital absence of pericardium have described including total absence, right-sided defects (complete or partial), left sided defects (complete or partial), and diaphragmatic defects (CUCCUINI, LISI, CONSOLI et al., 2013). As far as we know absence of the fibrous pericardium has not been reported and less noticed. Interestingly such seemingly unimportant 
variation accompanied with the abnormal diameter of the ascending aorta. The size and subdivisions of the aorta are less noticed in academic education, but seems to be clinically important. The size of the aorta decreases with distance from the aortic valve in a tapering fashion (ERBEL, ALFONSO, BOILEAU et al., 2001). The presented case showed an inverse fashion of tapering in face that the diameter of the proximal aorta was approximately two folds in comparison with its sinotubular. Admittedly such anomalies in the size and shape of the ascending aorta could be considered a potentially life threatening factor that may lead to serious complications such as hypertension and aortic rapture (ERBEL and EGGEBRECHT, 2006). In conclusion, the presented case gives an additional emphasis on the necessity of the thorough knowledge of anatomical variations of the phrenic nerve for the safe and standard supraclavicular nerve blocking.

\section{References}

AKTAN, ZA., OZTURK, L., BILGE, O., OZER, MA. and ATMAZB PY. A cadaveric study of the anatomic variations of the brachial plexus nerves in the axillary region and arm. Turkish Journal of Medical Science, 2006, vol. 31, p. 147-150.

BANNEHEKA, S. Morphological study of the ansa cervicalis and the phrenic nerve. Anatomical Science International, 2008, vol. 83, n. 1, p. 31-44. PMid:18402086. http://dx.doi.org/10.1111/j.1447073X.2007.00201.x.

BERGMAN, RA., THOMPSON, SA., AFIFI, AK. and SAADEH, FA. Compendium of human anatomic variation. Baltimore: Urban and Schwarzenberg, 1988. p. 138-139.

BIGELEISEN, PE. Anatomical variations of the phrenic nerve and its clinical implication for supraclavicular block. British Journal of Anaesthesia, 2003, vol. 91, n. 6, p. 916-917. PMid:14633767. http://dx.doi.org/10.1093/bja/aeg254.

CLEMENTE, CD. Anatomy of the human body. 30th ed. Philadelphia: Lea \& Febiger, 1985. p. 1203-1205

CUCCUINI, M., LISI, F., CONSOLI, A., MANCINI, S., BELLINO, V., GALANTI, G. and CAPACCIOLI, L. Congenital defects of pericardium: case reports and review of literature. Italian Journal of Anatomy and Embryology, 2013, vol. 118, n. 1, p. 136-150. PMid:23898583.
DAYAL, S. and KY, M. The Variations in the root of origin of the phrenic nerve. Journal of Mahatma Gandhi Institute of Medical Sciences, 2009, vol. 14, n. ii, p. 24-27.

ELLIS, H. Heart and mediastinum: heart and great vessels. New York: Elsevier Churchill, 2005.

ERBEL, R., ALFONSO, F., BOILEAU, C., DIRSCH, O., EBER, B., HAYERICH, A., RAKOWSKI, H., STRUYYEN, J., RADEGRAN, K., SECHTEM, U., TAYLOR, J., ZOLLIKOFER, C., KLEIN, WW. and MULDERB, LA. Diagnosis and management of aortic dissection. European Heart Journal, 2001, vol. 22, n. 18, p. 1642-1681. http:// dx.doi.org/10.1053/euhj.2001.2782.

ERBEL, R. and EGGEBRECHT, H. Aortic dimensions and the risk of dissection. Heart (British Cardiac Society), 2006, vol. 92, n. 1, p. 137-142. PMid:16365370. http://dx.doi.org/10.1136/ hrt.2004.055111.

KOO, CW. and NEWBURG, A. Congenital absence of the right pericardium: embryology and imaging. Journal of Clinical Imaging Science, 2015, vol. 5, p. 5-12. http://dx.doi.org/10.4103/21567514.152338. PMid:25861546.

MADHYSTHA, S. and BHAT, SM. Anomalous phrenic nerve: a case report. Neuroanatomy, 2006, vol. 5, p. 47-49.

MAK, PH., IRWIN, MG., OOI, CG. and CHOW, BF. Incidence of diaphragmatic paralysis following supraclavicular brachial plexus block and its effect on pulmonary function. Anaesthesia, 2001, vol. 56, n. 4, p. 352-356. PMid:11284823. http://dx.doi.org/10.1046/j.13652044.2001.01708-2.x.

MENDELSOHN, AH., DECONDE, A., LAMBERT, HW., DODSON, SC., DANEY, BT., STARK, ME., BERKE, GS. and WISCO, JJ. Cervical variations of the phrenic nerve. The Laryngoscope, 2011, vol. 121, n. 9, p. 1920-1923. http://dx.doi.org/10.1002/lary.21894. PMid:22024845.

TARIG, S., MAHMOOD, S., MADEIRA, S. and TARASOV, E. Congenital complete absence of pericardium masquerading as pulmonary embolism. Heart Views, 2013, vol. 14, n. 1, p. 29-32. PMid:23580923. http://dx.doi.org/10.4103/1995-705X.107118.

Received August 24, 2015 Accepted November 8, 2016 